\title{
SIM Brasil study - Women's Gastrointestinal Health: gastrointestinal symptoms and impact on the Brazilian women quality of life
}

\author{
Ana Paula Wolf Tasca DEL’ARCO, Pamela MAGALHÃES and Flávio Antônio QUILICI
}

Received 5/9/2016

Accepted 10/1/2017

ABSTRACT - Background - Gastrointestinal symptoms seem to affect more women, due to hormonal and emotional issues, impacting the quality of life. The emotional state can affect the bowel functioning through a bidirectional communication system between the gut and the brain involving the neuroendocrine system. Altered bowel functioning and gastrointestinal symptoms can alter quality of life. Objective - The SIM study aimed to describe, characterize and quantify gastrointestinal symptoms reported by Brazilian women, their causes, feelings and impact. Methods - A structured electronic questionnaire was developed following qualitative phase for semantic formatting, and was administered to volunteer women in ten Brazilian cities. Descriptive and Bayesian statistics analyses were used. Results - From the 3029 respondent, 66\% reported gastrointestinal symptoms. The most prevalent symptoms were gases (46\%), abdominal distention and constipation (43\%). The main causes were lifestyle and eating habits. Gastrointestinal symptoms affected quality of life in most women $(62 \%)$, especially constipation ( $\operatorname{mood}(89 \%)$, concentration $(88 \%)$ and sexual life $(79 \%))$. Most common solutions were drinking water, teas, eating foods rich in fiber and probiotics. Conclusion - Gastrointestinal symptoms are highly prevalent in Brazilian women and negatively impact different aspects of quality of life (mood, concentration and sexuality). The bowel is an important emotional catalyst that can modulate the psychologic behavior. Better understanding of the interaction between the gut and the brain should help in the management of gastrointestinal symptoms to improve women's quality of life.

HEADINGS - Gastrointestinal tract. Women's health. Quality of life. Surveys and questionnaires.

\section{INTRODUCTION}

Gastrointestinal (GI) symptoms are quite frequent in the population, and some of the symptoms are common, such as constipation, diarrhea, bloating, abdominal pain and distension, although their prevalence are little known, mainly in Latin countries $^{(4,10,18,23,33,36,38,40)}$. Gastrointestinal symptoms encompass different digestive symptoms that are widely observed in the general population $^{(38,40)}$. The type, frequency and intensity of these symptoms vary between subjects ${ }^{(23)}$, and may impact their daily life ${ }^{(38)}$. Abdominal pain/discomfort and bloating are often reported as the more troublesome and frequent symptoms, especially in patients with irritable bowel syndrome (IBS) ${ }^{(4,36)}$. Due to hormonal issues, it is assumed that women are most affected by them, especially with regard to constipation ${ }^{(32)}$.

When these symptoms, generally associated to multiple factors, cannot be explained by any abnormality in the structure of the organs or biochemical markers, the GI symptoms is defined as a functional bowel disorder, such as irritable bowel syndrome (IBS) and functional constipation ${ }^{(6,10,12,21)}$. When the etiology of the problem is related to the structural or biochemical function, the problem is defined as organic ${ }^{(10)}$. According to Costa et al. ${ }^{(10)}$, differentiate a functional bowel disorder from an organic disease is essential to alleviate the impact on the lives of patients and the public health service.
The installation of functional bowel disorders is directly related to lifestyle, and insufficient physical activity and poor diet are factors that can determine this scenario ${ }^{(16,32)}$. The emotional and stress state of the subject, factors comprising the lifestyle, are also closely related to GI symptoms ${ }^{(17,20,30)}$. Women seem to be more affected emotionally and have their quality of life (QoL) more affected by them than men ${ }^{(1)}$.

The perception of the bowel may be affected by the emotional state of the individual. Currently, the study of the relationship between the bowel and brain is being widely spread. In the gut-brain axis, there is clear reciprocal relationship between these two major organs, where the operation of one influences the other. The corticotropin-releasing hormone - serotonin - is an important mediator of stress responses, influencing the brain and bowel ${ }^{(17,20,21,30)}$. The neuroendocrine system, and in particular, serotonin, are currently considered relevant factors in the context of GI symptoms because they relate to the functioning of the bowel ${ }^{(10,14,22,24)}$. The literature has shown that the composition of the intestinal microbiota also interferes with brain activity in humans, especially in the regions that control the sensations and emotions ${ }^{(39)}$.

Understanding how the QoL of healthy subjects can be affected by GI symptoms is an expanding area of research ${ }^{(18)}$, with experimental designs drawn by the fascinating organic relationship of the gut-brain axis. In this context, this study is justified by the scarce scientific literature on intestinal health of Brazilian women,

Declared conflict of interest of all authors: none

Disclosure of funding: no funding received

Disclosure statement: This study was granted by Danone Research.

Pontifícia Universidade Católica de Campinas, SP Brasil.

Correspondence: Ana Paula Wolf Tasca Del'Arco. Ângelo Cal, 300 - Q1 Lt21 - CEP: 15093-110 - São José do Rio Preto, SP, Brasil. E-mail: apwt.delarco@gmail.com 
especially in relation to the prevalence of GI symptoms and their impact on the QoL of the female population. The purposes of this study is describe, characterize and quantify the main GI symptoms reported by Brazilian women, their causes, the sensations related and the impact of these GI symptoms on the Brazilian women QoL, as well as the solutions adopted by women against the GI symptoms.

\section{METHODS}

Observational study on a national scale, conducted in two phases, as follows.

\section{Qualitative phase}

This stage aimed to characterize the main profiles of women who reported GI symptoms and identify how these women expressed such problems, through sensations and images. Individual interviews with psychologists (lasting an hour and a half) and individual journaling for 15 days were conducted with 21 female volunteers (aged from 25 to 70 years, in the city of São Paulo). At this stage, through the journal, the women were able to report in depth the feelings in the very moment they were experiencing them, also expressing their feelings through drawings and images. In the interviews, it was possible to access and discuss the individual experiences of each one of them.

\section{Quantitative phase}

Based on the results obtained in the qualitative phase, we structured a questionnaire entitled "Tell us the story of your latest GI problem" with 49 questions. At the beginning, through a list of symptoms, the women were asked to indicate the different GI symptoms that might concern them in general and to report whether they were "often", "occasionally" or "not at all" concerned by GI symptoms. After that, the questionnaire focused on the most recent GI symptom and asked to the women identified it from a list of usual symptoms previously described, associating this GI symptom with a series of pictures and images representing their sensations during the episode ${ }^{(7,8)}$.

The questionnaire was very didactical including general instructions at the beginning and at the sub sections in order to facilitate the understanding and the questions were focused on time, place of occurrence, severity, supposed trigger and consequences (social, emotional and physical) of the last GI symptom experienced, including the main strategies adopted to management the situation. The language was friendly and the structure was multiple choice. Here is an example of a question and the possible answers showed in Figure 1.

\begin{tabular}{||l|l|l|}
\hline Today/yesterday & \\
\hline One week ago & \\
\hline 2 weeks ago & \\
\hline 1 month ago & \\
\hline In the morning & \\
\hline In the afternoon & \\
\hline In the evening & \\
\hline \begin{tabular}{l|l|l|} 
In my sleep (night time or \\
nap)
\end{tabular} & \\
\hline In the week & \\
\hline At the weekend & \\
\hline
\end{tabular}

FIGURE 1. Example of possible answers, where only one choice was possible, to the questionnaire question: "Describe your circumstances when your latest GI problem you are telling us about started"
The questionnaire was made available electronically (web survey), self-administered, for women to access and fill in their homes, what facilitated the ability to complete the survey in the privacy of their homes and anonymously which encourages more truthful answers and the ability to complete the survey at the respondent's convenience.

In this data collection way (web survey), the respondents were not influenced by the interviewer, and the information could be collected in a variety of locations from a large number of respondents (sample size) with increased power of the statistical analysis. The sample consisted of 3.029 women who were selected voluntarily, to achieve a number of 2.000 women who reported some GI symptom. Pregnant women and those who had very serious digestive complaints were excluded. The selected women were from ten Brazilian capitals (São Paulo, Rio de Janeiro, Belo Horizonte, Curitiba, Porto Alegre, Salvador, Recife, Fortaleza, Manaus and Federal District-Brasilia), aged from 18 to 60 years, of classes A, $\mathrm{B}$ and $\mathrm{C}$ according to the economic classification criteria in Brazil, of the Brazilian Association of Research Companies (ABEP) $)^{(11)}$.

\section{Statistical tests}

With the descriptive statistical analysis, we obtained the frequency of GI symptoms, when they occurred, the reported causes, symptoms and sensations attributed by women, commonly used solutions and impact on QoL.

By grouping the type of symptoms, with Bayesian statistical analysis, we defined sets (clusters) of GI symptoms and their consequences related to age group, social class and regions of the country.

\section{RESULTS}

\section{Qualitative phase}

Four women profiles were identified based on their behavior in relation to the way they related to the GI symptoms they reported. These profiles have been defined from the way of involvement women had with their GI symptoms, which moved in a shaft that went from emotional to rational; and how women dealt with the problem, what was its management measures, which transitioned from functional to emotional. Figure 2 shows the main charac-

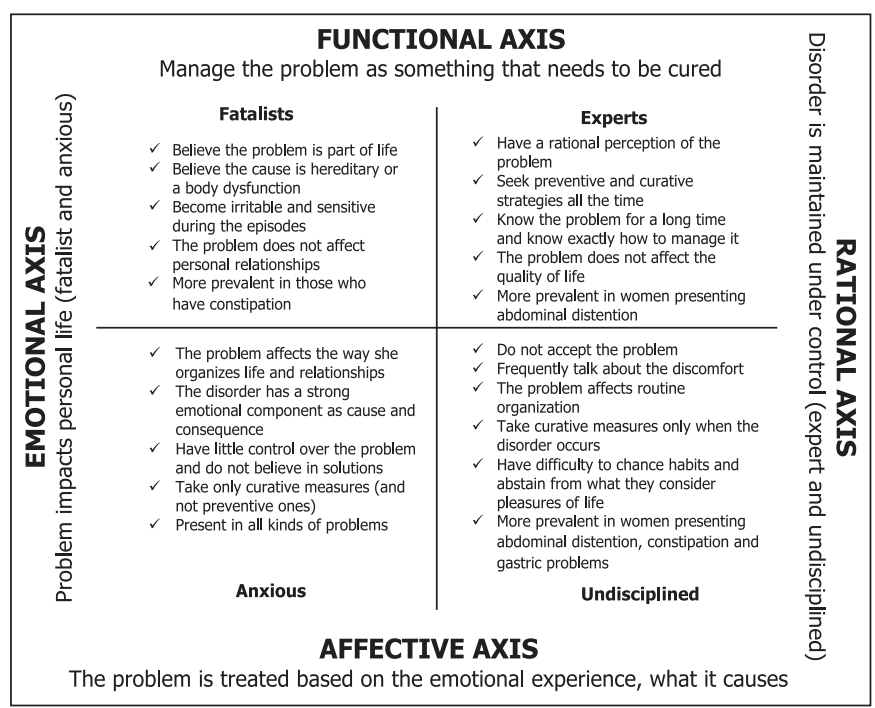

FIGURE 2. Women profiles identified in the qualitative phase 
teristics of the four profiles found: fatalistic, experts, anxious and undisciplined.

Based on the reports of these women, four categories of GI disorders were also identified (constipation, diarrhea, gastric heaviness and abdominal distention), as well as how women expressed such problems through sensations reported and images associated with these problems (Figure 3).

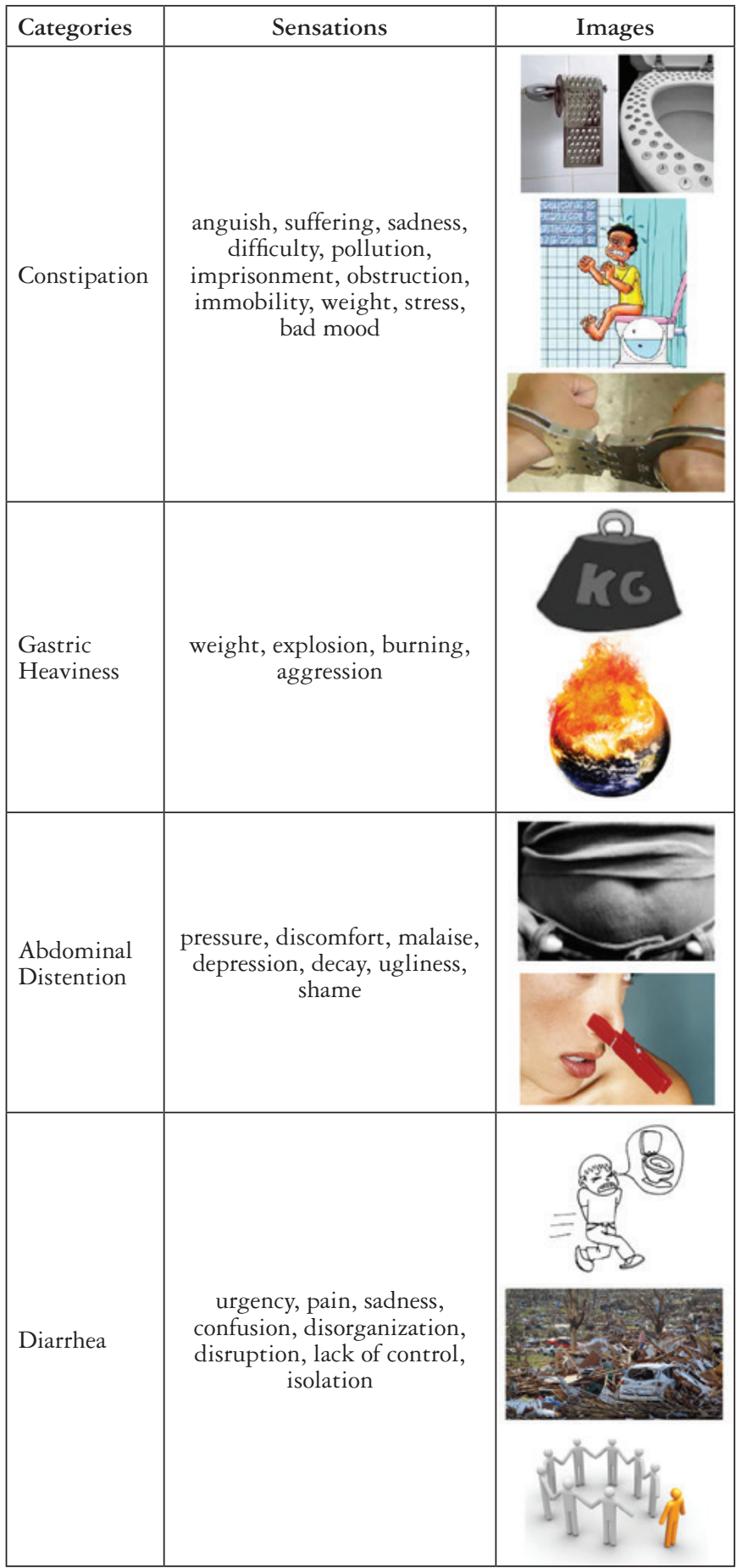

FIGURE 3. Main sensations and images associated with the categories of gastrointestinalconditions
Important findings were reported by the women during this study phase: i) to go to the bathroom outside home is an obstacle to meet their physiological needs; ii) they feel fear and shame, when other people could notice what they were doing in the bathroom.

\section{Quantitative phase}

Of the 3029 women who responded to the questionnaire, 2000 reported GI symptoms, that is, two out of every three women. Of these, $46 \%$ reported having the problem weekly, $8 \%$ monthly and $12 \%$ every two months or less. Most women $(72 \%)$ stated that the problems occurred during the week and almost half (42\%) reported having the last GI symptom less than a week before.

The respondent study sample who reported GI symptoms showed the following distribution according to age group: $48 \%$ between 18 and 29 years, $28 \%$ from 30 to 39 years, $15 \%$ between 40 and 49 years, and $9 \%$ between 50 and 60 years. According to the classification by the Brazil criteria $^{(11)}, 17 \%$ of women were from the social class defined as A, $51 \%$ belonged to class B and $32 \%$ to class $\mathrm{C}$ (considering the respondent study sample). The geographical distribution of the respondent sample was 3\% in the North, $10 \%$ in Northeast, $7 \%$ in the Midwest, $63 \%$ in the Southeast and $17 \%$ in the South regions.

Among the causes for GI symptoms, those related to lifestyle that were reported most frequently were stress (61\%) and insufficient physical activity $(52 \%)$. Among the causes related to eating habits, $77 \%$ of women reported the consumption of fatty foods as the main cause of GI symptoms, and $46 \%$ of them said it was the sparkling water or soft drinks. The hasty lifestyle that includes the work routine and lack of time was mentioned as a major impediment for women to adopt a healthier lifestyle, controlling stress, practicing more physical activities and having a more balanced diet. Women mentioned some specific situations as aggravating to the problem, as eating in a hurry, staying seated for long periods, anxiety and stress.

Sensations reported in this stage of the research were quantified as shown in Table 1, which also displays the images associated with the sensations as they were presented in the questionnaire.

TABLE 1. Frequency of sensations reported by women

\begin{tabular}{lcc}
\hline Sensations & Frequency (\%) & Questionnaire images \\
\hline $\begin{array}{l}\text { Abdominal } \\
\text { Distention / Weight }\end{array}$ & 29 \\
Burning & 21 \\
Gripes & 17 \\
Lazy Intestine & 14 \\
Bubbling & \\
None & 11
\end{tabular}


According to the typology of the symptoms, the Bayesian statistical analyzes defined 13 sets (clusters) as shown in Table 2. The most prevalent symptoms were gases in $46 \%$, and abdominal distention and constipation, both in $43 \%$. The sets (clusters) most prevalent in the age group from 18 to 29 years were the clusters 2,6 and 11 . The cluster 1 was the most prevalent for the age groups from 30 to 39 years and from 40 to 49 years. For the age group from 50 and 60 years, the most prevalent was cluster 7 . There was no statistical difference between them for social class and geographic region.

TABLE 2. Definition and occurrence of clusters based on the type of symptoms

\begin{tabular}{|c|c|c|}
\hline Cluster & Occurrence & Symptoms \\
\hline 1 & $9.8 \%$ & $\begin{array}{l}\text { Constipation + abdominal distention + } \\
\text { weight }+ \text { gas }+ \text { spasm }+ \text { bubbling }+ \\
\text { plentiful stool + painful evacuation }+ \\
\text { body pain }\end{array}$ \\
\hline 2 & $10.3 \%$ & $\begin{array}{l}\text { Constipation + gases + bubbling + } \\
\text { plentiful stool + painful evacuation }\end{array}$ \\
\hline 3 & $7.9 \%$ & $\begin{array}{l}\text { Abdominal distention }+ \text { weight }+ \text { gases }+ \\
\text { plentiful stool }+ \text { painful evacuation }+ \\
\text { body pain }+ \text { constipation }\end{array}$ \\
\hline 4 & $5.3 \%$ & Full + bloated stomach \\
\hline 5 & $7.4 \%$ & Constipation + painful evacuation + gases \\
\hline 6 & $7.8 \%$ & Constipation + painful evacuation \\
\hline 7 & $5.9 \%$ & $\begin{array}{l}\text { Diarrhea }+ \text { weight }+ \text { abdominal } \\
\text { distention }+ \text { gases }+ \text { bubbling }+ \text { spasms }+ \\
\text { plentiful stool }+ \text { acid reflux }+ \text { body pain }\end{array}$ \\
\hline 8 & $5.1 \%$ & Bubbling + spasms + gases + diarrhea \\
\hline 9 & $7.4 \%$ & Nausea + bloated stomach \\
\hline 10 & $7.1 \%$ & $\begin{array}{l}\text { Weight }+ \text { pressure }+ \text { bloated stomach }+ \\
\text { acid reflux + body pain }\end{array}$ \\
\hline 11 & $7.5 \%$ & Diarrhea + cramps \\
\hline 12 & $7.4 \%$ & Plentiful stool \\
\hline 13 & $11.0 \%$ & Bubbling \\
\hline
\end{tabular}

In an effort to "solve" the disorders, $73 \%$ of women reported drinking water, $40 \%$ reported taking herbal tea, $38 \%$ reported eating foods rich in fiber, $36 \%$ reported consuming probiotic yogurt, $34 \%$ reported eating papaya and 33\% reported eating yogurt was the strategy adopted. None of the women who answered the questionnaire sought medical help to solve GI symptoms. They justified this behavior with the reasons described in Table 3 .

TABLE 3. Frequency of the reasons why women who reported gastrointestinal conditions did not seek medical attention

\begin{tabular}{lc}
\hline Reason & Frequency (\%) \\
\hline I do not consider it a disease & 25.5 \\
I expect the problem to be solved on its own & 20 \\
$\begin{array}{l}\text { I take medications that do not require a } \\
\text { prescription }\end{array}$ & 18.5 \\
$\begin{array}{l}\text { Doctors do not treat this problem seriously } \\
\text { enough }\end{array}$ & 17 \\
$\begin{array}{l}\text { I know that the cause is my poor eating habits, } \\
\text { so I take medicine }\end{array}$ & 5 \\
Other & 14 \\
\hline
\end{tabular}

Most women (62\%) reported that GI symptoms affected their QoL in general. Almost $70 \%$ of them said that the problems interfered in the mood, $66 \%$ said they affect the concentration and $57 \%$ state they affected their sex life (Figure 4). Assessing specifically women who reported any problem related to the slow intestinal transit time, it was found that the impact on their QoL was even more significant: for $89 \%$ there was an impact on mood, for $88 \%$ there was an impact on concentration and for $79 \%$ on sexual life.

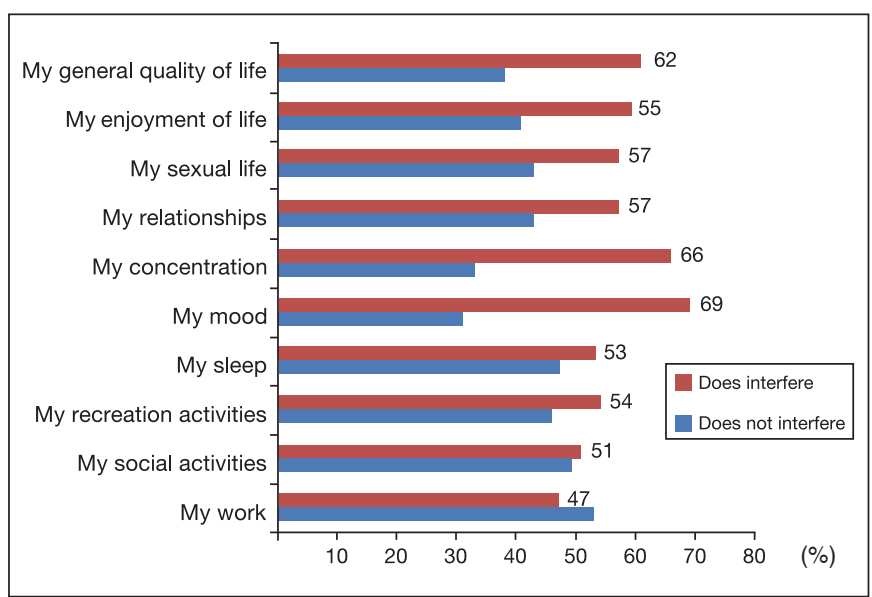

FIGURE 4. Gastrointestinal conditions impact on Brazilian women quality of life

\section{DISCUSSION}

The SIM (Women's Gastrointestinal Health) study allowed for the first time a representative and comprehensive evaluation of the intestinal health of Brazilian women, once that this study is the first one done in country and also in Latin America on this topic. According SIM study, in Brazilian female population, the GI symptoms are related by two-thirds of women, affecting their QoL, showing that this is an important topic to be discussed and addressed in medical community. The main GI symptoms reported were functional and the main causes attributed by women were those related to lifestyle and to eating habits, affecting their QoL in general (mainly mood, concentration and sexual life).

According Longstreth et al. ${ }^{(23)}$, the IBS symptoms are predominant in female population occurring in $10 \%$ to $20 \%$ of adults and adolescents around the world, and these symptoms come and go over time impacting QoL. The main symptoms are bloating (present in $96 \%$ of IBS patients, more prevalent in women); constipation (present in around $30 \%$ of people throughout the world and also more common in women); and functional diarrhea.

In Brazil, in a recent cross-sectional study performed in Florianópolis with 605 women, with 40 years old (median age), visiting a public health service for reasons that were not related with GI symptoms, the constipation was self-reported by $24.5 \%{ }^{(32)}$. Around the world, in a cross-sectional study in the USA, through telephone survey, 2510 subjects (men and women) answered questions about their GI symptoms in the month previous to the research, focusing on the frequency, duration, intensity and impact of symptoms, and $40.5 \%$ of respondents reported having had one or more symptoms in the previous month ${ }^{(33)}$. A study conduct in Netherlands, shows that $26 \%$ of the population reported GI symptoms, with a higher prevalence among female population, and flatulence $(71 \%)$, 
bloating $(63 \%)$ and borborygmi $(60 \%)$ were the most frequently symptoms $^{(38)}$. In a survey performed by Silva et al. ${ }^{(35)}$, it is estimated that constipation affects from $2 \%$ to $28 \%$ of the population in Western countries, and it is difficult to estimate the true prevalence of this problem because there are different classifications for diagnosis. These studies reinforce the importance of findings of this SIM study, where $66 \%$ of the Brazilian women had some type of GI symptoms with significant impact on their QoL.

The causes of GI symptoms considered functional are related to multiple factors, and lifestyle seem to be play an important role in this process $s^{(2,21,34,35)}$. It is known that diet composition is extremely important to bowel function ${ }^{(16)}$ and the stress also exerts great influence on the functioning of the GI tract ${ }^{(17,20)}$. Also, the lifestyle is a factor responsible for the composition of the intestinal microbiota $^{(3,25)}$ and stress can directly affect its composition ${ }^{(5,30)}$. According to Bailey et al. ${ }^{(5)}$, exposure to stress affects the stability of the microbiota and may result in bacterial translocation. The diet also changes the composition of the microbiota ${ }^{(19)}$, which in turn can determine bowel function. According to Annalisa et al. ${ }^{(3)}$, intestinal microbiota is influenced by several factors such as age, diet habit and lifestyle.

The human body is populated by a multitude of microorganisms called human microbiota. They inhabit surfaces of the human body ${ }^{(5)}$, with a genetic diversity superior to men, since they make up to 100 trillion cells, which is ten times more than the number of human cells ${ }^{(27)}$. Many of these microorganisms are part of the intestinal microbiota, with over 500 species of bacteria, which due to such expressive characteristics have an ability to interact with their host, impacting their health and well-being ${ }^{(5,6,9,15,18,25,27)}$. The composition of the intestinal microbiota may be related to GI symptoms, mainly related to abdominal pain and abdominal distention. According to Jalanka-Tuovine et al. ${ }^{(18)}$, subjects who had abdominal pain showed five times less Bifidobacterium than those without pain. Also, may be related with well-being. In a study with rats, Bercik et al. ${ }^{(6)}$ concluded that the composition of the intestinal microbiota influences behavior and brain chemistry, and GI symptoms and intestinal dysbiosis can contribute to psychiatric disorders. Tillisch et al. ${ }^{(39)}$ conducted a study with women to investigate the relationship between brain function and probiotic yogurt consumption, which acts in the modulation of the intestinal microbiota. The authors concluded that the consumption of fermented yogurt with probiotics (for 4 weeks, 250 grams per day) interferes with brain activity, with greater emphasis on regions of emotions and sensations ${ }^{(39)}$.

It is important to note that the way the slow intestinal transit is seen in society directly affects the occurrence of GI symptoms and may even be their cause. This fact is seen as a taboo especially among women and has a psychological impact, since in this SIM study (during the first phase) they reported that the fact of having to go to the bathroom outside home is an obstacle to meet their physiological needs. Thus slowing the defecation reflex, an essential factor that causes constipation. The anal sphincters are a complex system between the inner smooth muscle, the striated muscle and the external puborectalis muscle, which are organized to execute fecal continence mechanism in conjunction with a network of nerves and the central nervous system ${ }^{(28,29,31)}$. According to Rajasekaran et al. ${ }^{(29)}$, the internal smooth muscle is primarily responsible for the pressure of the anal canal on rest and the external striated muscle has greater responsibility on the increase in anal canal pressure, with voluntary tightening of the sphincter. The behavior of inhibiting the reflection of the anal sphincter, slowing it, can contribute to constipation. According to Oliveira et al. ${ }^{(26)}$, constipation is more prevalent in women, and among the factors that could explain this scenario, in addition to psychological and hormonal issues, are births and gynecological surgeries that can damage the pelvic muscles and their innervation. In postmenopausal women, genital prolapses are more frequent and also help to explain constipation ${ }^{(26)}$.

The emotional aspect related to the functioning of the bowel is often overlooked, but imprints an important relationship with it $^{(17)}$. Serotonin, a hormone related to wellbeing sensation, is closely related with the bowel ${ }^{(10)}$, since most of this hormone is synthesized, stored and released in the intestine ${ }^{(24)}$. The enterochromaffin cells are neuroendocrine cells in the mucosa of the GI tract and are responsible for the serotonin synthesis ${ }^{(14,22,24)}$. According to Mawe and Hoffman ${ }^{(24)}$, serotonin is altered in patients with GI symptoms, especially with the slow intestinal transit, a factor that impacts the individual's wellbeing sensation. The corticotropin-releasing hormone acts on the gut-brain axis, mediating stress responses and influencing both brain and intestine, and the perception of the latter is affected by the emotional state of the subject ${ }^{(17,21,30)}$.

The age range is related to gastrointestinal symptoms and their occurrences. In the present study, it was observed that the symptoms of clusters 1 and 7 were the most frequent in the age groups that includes the menopause and postmenopausal period (ranging in this study from 40 up to 60 years). These sets (clusters) are the ones that concentrate the largest combination and variety of symptoms, which might be related to the tangle of feelings that affect women in these age groups due to the hormonal decline that is characteristic of menopause.

Empirically, women relate dietary factors as an adjunct in the solution of GI symptoms. In addition to the increased consumption of fiber and water ${ }^{(34)}$, probiotic yoghurt is an important factor in the improvement of GI symptoms, since the probiotic microorganisms are able to modulate the intestine microbiota and determine bowel function. In a review study conducted by Waitzberg et al. ${ }^{(41)}$, the authors evaluated two clinical trials on the action of a fermented milk product with Bifidobacterium animalis lactis CNCM I-2494 and four other probiotics on the health of the host, especially with regard to digestive health and the functions of the GI tract. It was found that consumption of the product for four weeks had health benefits for healthy women, with a significant decrease in GI symptoms and increased digestive comfort ${ }^{(41)}$. Probiotics, by imprinting a relationship with the intestinal functions, contribute to the health and wellbeing of the subject(9,13). This fact was also observed in the SIM study, where some women were using probiotics to solve their GI problems, especially those with slow intestinal transit.

Negative impact on QoL in healthy subjects can be one of the disorders generated by GI symptoms ${ }^{(18)}$. In a Brazilian study, performed in Florianópolis, with 605 adult women, visiting a public health service for reasons that were not related with GI symptoms, $25.1 \%$ had the diagnosis for constipation and about $80 \%$ of them stated that constipation had medium or great interference in their lives ${ }^{(32)}$. The SIM study showed similar results, where GI symptoms affected the QoL in general of the most of the evaluated women.

Around the world, other studies showed similar data. In a study conducted in France with 253 subjects with IBS, through telephone survey, Amouretti et al. ${ }^{(1)}$ found that those subjects with IBS had lower QoL scores, statistically significant when compared with the French general population. Low scores in HRQoL (Health-Related Quality of Life) were correlated with greater intensity of abdominal 
pain and discomfort. The same results were found in Netherlands, comparing the population with and without GI symptoms: the impact on the QoL was significantly more negative in the population with GI symptoms $(P<0.01)^{(38)}$. Another study of Sandler et al. ${ }^{(33)}$ showed that $65 \%$ of respondents reported that the symptoms had moderate to severe intensity and that these symptoms affected daily activities, impacting significantly the day-to-day life of the American population studied. Daily activities such as work, are affected by GI symptoms, which impacts on the economy. In a study by Sun et al. ${ }^{(37)}$, with data from the National Health and Wellness Survey (NHWS), where 1.430 subjects had chronic constipation, the authors found a statistically significant impact $(P<0.01)$ of this health condition with the loss of productivity at work, with more absenteeism in those with chronic constipation compared with the control group ( $9.08 \%$ vs $5.20 \%)$.

GI symptoms are seen as harrowing and stressful by most women. According to Amouretti et al. ${ }^{(1)}$, women's QoL is most affected by GI symptoms. Once the GI problem happens, many women deal with it with distress and anxiety, which acts against the improvement of symptoms and so on in a vicious cycle, a behavior complicating the other, confusing cause and consequence of the problem. As previously mentioned in results section, most of women said that their problems occurred during the week, i.e. on working days, which may be related to the period of increased stress and haste of women. Anxiety and depression are related to mood swings, which have great influence in the GI tract, contributing to the occurrence of functional bowel disorders ${ }^{(17)}$.

Besides this psychological scenario of stress and anxiety, feelings of shame are assigned to the act of defecating. Some women in the SIM study said (in the first phase) that the mere fact that other people could notice what they were doing in the bathroom, make them feel fear and shame. Such event can be explained precisely by the association of evacuation to the feeling of rejection, threatening the human search for belonging and acceptance. For Sandler et al. ${ }^{(33)}$, women were more likely to report their problems than men when they were not related to the stool itself, but for diarrhea or sift stool, the numbers were similar between women and men $(27.1 \% \text { vs } 26.7 \%)^{(33)}$. This relationship between the stool and the emotional commitment was also reported by Amouretti et al. ${ }^{(1)}$, who observed in his study in the French population that subjects with diarrheal IBS had a worse emotional domain score in HRQoL when compared to the scores of individuals with IBS with constipation predominance.

Functional bowel disorders should not be seen as less important neither by the population that suffers from them or health professionals. The education of professionals on the matter, with the correct and transparent approach to the subject with their patients can ease the intensity, frequency and duration of them. It is known that the adoption of a healthier lifestyle, effectively contributes to the treatment of functional bowel disorders ${ }^{(2,21,34,35)}$. It is the role of health professionals to advise and recommend to their patients the adoption of a healthier lifestyle, an attitude that would cause them to have an adequate motility and consequently decrease the consumption of laxative medications. The exceptions would be for those with chronic constipation, where laxatives are indicated, under medical supervision, as initial part of the treatment ${ }^{(34)}$. The misuse and abuse of laxatives may cause unnecessary side effects and major impacts on the health of subjects, since these substances can cause side effects and change motor, secretory and absorptive functions of the GI tract ${ }^{(2,34)}$.

Is important to reinforce that the SIM study is the first one done in Brazil and Latin America, allowing a representative and comprehensive evaluation of the intestinal health of Brazilian women for the first time. Its data allow some considerations: i) educational measures are necessary for clarification of the population that bowel function is a normal physiological function, which acts directly to the proper functioning of the organism as a whole, including the mental and emotional aspects; ii) besides the general population, health professionals should be better instructed to have a more transparent approach to GI symptoms with their patients, which certainly ease the psychological impact of talking about this topic, as well as physiologically abbreviate intensity, frequency and duration of GI symptoms; and iii) its demystifying is critical, as it is still seen as a taboo by society, especially in the female population.

One of the main limitations of the second phase of the study, related to the way of questionnaire administration (web survey), was the possible lack of access to the Internet. Also, language, cultural differences and regional expressions that exist in the different parts of the country, and the potential for respondents to misunderstand questions or the terms being used. In this survey, the use of items that were easy to understand and images to facilitate communication, minimized this latter risk.

\section{CONCLUSION}

This observational study on national scale shows that GI symptoms are present in the day-to-day life of two-thirds of Brazilian women without social class distinction and in all regions of the country, affecting more significantly their QoL. The main GI symptoms reported were functional and the causes attributed by women were those related to lifestyle and eating habits.

Most of the evaluated women reported that GI symptoms af fected their QoL in general, affecting mainly mood, concentration and sexual life. Such evidence allows to conclude that the bowel, because of its tenuous connection with the brain, becomes an important emotional catalyst, and may modulate negatively the psychological behavior of women, giving rise to a psycho-physiological vicious cycle that begins with negative feelings such as low self-esteem, stress, distress, anger and anxiety, triggering intestinal discomfort, which through their physical symptoms, reports the internal imbalance in the female body. Thus, uncomfortable with the GI reactions, the QoL of these women is directly affected, which invariably aggravate and make chronic the emotions that stimulate the initial cycle.

Social standards and lifestyle directly affect the female perspective on the intestine as an organ. The confrontation of the taboo of evacuating as a natural need is critical, requiring public awareness that the intestine is part of the body, and that with all its complexity of operation, it has immense relevance.

\section{Authors' contributions}

Del'Arco APWT: research implementation, data analysis, text editing. Magalhães P: data analysis, text revision. Quilici FA: research coordination, data analysis, text revision. 
Del'Arco APWT, Magalhães P, Quilici FA. Estudo SIM Brasil - Saúde Gastrointestinal da Mulher: sintomas gastrointestinais e o impacto na qualidade de vida da mulher brasileira. Arq Gastroenterol. 2017;54(2):115-22.

RESUMO - Contexto - Sintomas gastrointestinais parecem afetar mais as mulheres, devido a problemas hormonais e emocionais, afetando a qualidade de vida. O estado emocional pode afetar o funcionamento do intestino por meio de um sistema de comunicação bidirecional entre o intestino e o cérebro que envolve o sistema neuroendócrino. Alterações da função intestinal e sintomas gastrointestinais podem afetar a qualidade de vida. Objetivo - O estudo SIM teve como objetivo descrever, caracterizar e quantificar os sintomas gastrointestinais relatados por mulheres brasileiras, suas causas, sentimentos e impacto. Métodos - Questionário eletrônico estruturado foi desenvolvido após a fase qualitativa para formatação semântica, e foi administrado a mulheres voluntárias em 10 cidades brasileiras. Foram realizadas análises estatísticas descritivas e Bayesiana. Resultados - A partir dos 3029 respondentes, 66\% relataram sintomas gastrointestinais. Os sintomas mais prevalentes foram gases (46\%), distensão abdominal e constipação (43\%). As principais causas relatadas foram estilo de vida e hábitos alimentares. Sintomas gastrointestinais afetaram a qualidade de vida da maioria das mulheres (62\%), especialmente a constipação (humor ( $89 \%$ ), concentração ( $88 \%$ ) e vida sexual (79\%)). As soluções mais comuns adotadas foram beber água, chás, comer alimentos ricos em fibras e probióticos. Conclusão - Sintomas gastrointestinais são altamente prevalentes nas mulheres brasileiras e impactam negativamente diferentes aspectos da qualidade de vida (humor, concentração e sexualidade). O intestino é um catalisador emocional importante que pode modular o comportamento psicológico. Melhor compreensão da interação entre o intestino e o cérebro pode ajudar na gestão dos sintomas gastrointestinais para melhorar a qualidade de vida das mulheres.

DESCRITORES - Trato gastrointestinal. Saúde da mulher. Qualidade de vida. Inquéritos e questionários.

\section{REFERENCES}

1. Amouretti M, Le Pen C, Gaudin AF, Bommelaer G, Frexinos J, Ruszniewski P, et al. Impact of irritable bowel syndrome (IBS) on health-related quality of life (HRQoL). Gastroenterol Clin Biolog. 2006;30:241-6.

2. Andre SB, Rodriguez TN, Moraes Filho JPP. Constipação Intestinal. Rev Bras Med. 2000;57:15-7.

3. Annalisa N, Alessio T, Claudette TD, Erald V, Antonino L, Nicola D. Gut microbioma population: an indicator really sensible to any change in age, diet, metabolic syndrome, and life-style. Mediators Inflamm. 2014;2014:901308

4. Azpiroz F, Malagelada JR. The pathogenesis of bloating and visible distension in irritable bowel syndrome. Gastroenterol Clin North Am. 2005;34:257-69.

5. Bailey MT, Dowd SE, Galley JD, Hufnagle AR, Allen RG, Lyte M. Exposure to a social stressor alters the structure of the intestinal microbiota: Implications for stressor-induced immunomodulation. Brain Behavior Immun. 2011;25: 397-407.

6. Bercik P, Denou E, Collins J, Jackson W, Lu J, Jury J, et al. The intestinal microbiota affects central levels of brain-derived neurotropic factor and behavior in mice. Gastroenterol. 2011;141:599-609.

7. Carruthers HR, Miller V, Morris J, Evans R, Tarrier N, Whorwell PJ. Using art to help understand the imagery of irritable bowel syndrome and its response to hypnotherapy. Int J Clin Exp Hypn. 2009;57:162-73.

8. Carruthers HR, Morris J, Tarrier N, Whorwell PJ. Reactivity to images in health and irritable bowel syndrome. Aliment Pharmacol Ther. 2010;31:131-42.

9. Ciorba MA. A gastroenterologist's guide to probiotics. Clin Gastroenterol Hepatol. 2012;10:960-8.

10. Costa F, Mumolo MG, Marchi S, Bellini M. Differential diagnosis between functional and organic intestinal disorders: Is there a role for non-invasive tests? World J Gastroenterol. 2007;13:219-23.

11. Critério de Classificação Econômica Brasil. Associação Brasileira de Empresas de Pesquisa (ABEP). Available from: http://www.abep.org/criterio-brasil

12. Francesconi CF. Algoritmos diagnósticos da fundação Roma para sintomas gastrointestinais normais: apresentação. Arq Gastroenterol. 2012;49(s.1):6-8.

13. Gerritsen J, Smidt H, Rijkers GT, Vos WM. Intestinal microbiota in human health and disease: the impact of probiotics. Genes Nutr. 2011;6:209-40.

14. Gershon MD, Tack J. The serotonin signaling system: from basic understanding to drug development for functional GI disorders. Gastroenterol. 2007;132:397-414.

15. Holmes E, Li JV, Athanasiou T, Ashrafian H, Nicholson JK. Understanding the role of gut microbiome-host metabolic signal disruption in health and disease. Trends in Microbiol. 2011;19:349-59.

16. Howarth L, Petrisko Y, Furchner-Evanson A, Nemoseck T, Kern M. Snack selection influences nutrient intake, triglycerides, and bowel habits of adult women: a pilot study. J Amer Diet Assoc. 2010;110:1322-27.

17. Huerta-Franco MR, Vargas-Luna M, Tienda P, Delgadillo-Holtfort I, Balleza-Ordaz M, Flores-Hernandez C. Effects of occupational stress on the gastrointestinal tract. World J Gastrointest Pathophysiol. 2013;4:108-18.
18. Jalanka-Tuovinen J, Salonen A, Nikkila J, Immonen O, Kekkonen R, Lahti L, et al. Intestinal microbiota in healthy adults: Temporal analysis reveals individual and common core and relation to intestinal symptoms. PlosOne. 2011;6:e23035.

19. Kashyap PC, Marcobal A, Ursell LK, Larauche M, Duboc H, Earle KA, et al. Complex interactions among diet, gastrointestinal transit, and gut microbiota in humanized mice. Gastroenterol. 2013;144:967-77.

20. Konturek PC, Brzozowski T, Konturek SJ. Stress and the gut: pathophysiology, clinical consequences, diagnostic approach and treatment options. J Physiol Pharmacol. 2011;62:591-99.

21. Lee YJ, Park KS. Irritable bowel syndrome: Emerging paradigm in pathophysiology. World J Gastroenterol. 2014;20:2456-69.

22. Li HJ, Johnston B, Aiello D, Caffrey DR, Giel-Moloney M, Rindi G, et al. Distinct cellular origins for serotonin-expressing and enterochromaffin-like cells in the gastric corpus. Gastroenterol. 2014;146:754-64.

23. Longstreth GF, Thompson WG, Chey WD, Houghton LA, Mearin F, Spiller RC. Functional bowel disorders. Gastroenterol. 2006;130:1480-91.

24. Mawe GM, Hoffman JM. Serotonin signaling in the gastrointestinal tract: functions, dysfunctions, and therapeutic targets. Nat Rev Gastroenterol Hepatol. $2013 ; 10: 473-86$

25. Nicholson JK, Holmes E, Kinross J, Burcelin R, Gibson G, Jia W, et al. Host-gut microbiota metabolic interactions. Science. 2012;336:1262-67.

26. Oliveira SCM, Pinto-Neto AM, Góes JRN, Conde DM, Santos-Sá D, Costa-Paiva $\mathrm{L}$. Prevalência e fatores associados à constipação intestinal em mulheres na pós-menopausa. Arquiv Gastroenterol. 2005;42:24-9.

27. Qin J, Li R, Raes J, Arumugam M, Burgdorf KS, Manichanh C. et al. A human gut microbial gene catalogue established by metagenomic sequencing. Nature. 2010;464:59-65.

28. Raizada V, Bhargava V, Karsten A, Mittal RK. Functional morphology of anal sphincter complex unveiled by high definition manometery \& 3-dimensional ultrasound imaging. J Neurogastroenterol Motility. 2011;23:1013-28.

29. Rajasekaran MR, Jiang Y, Bhargava V, Littlefield R, Lee A, Lieber RL, et al. Length-tension relationship of the external anal sphincter muscle: implications for the anal canal function. American J Physiol Gastrointestinal and Liver Physiol. 2008;295:367-73.

30. Rodino-Janeiro BK, Alonso-Cotoner C, Pigrau M, Lobo B, Vicario M, Santos $\mathrm{J}$. Role of corticotropin-releasing factor in gastrointestinal permeability. J Neurogastroenterol and Motility. 2015;21:33-50.

31. Rodriguez L, Siddiqui A, Nurko S. Internal anal sphincter relaxation associated with bisacodyl-induced colonic high amplitude propagating contractions in children with constipation: a colo- anal reflex? J Neurogastroenterol Motility. 2012;24:1023-39.

32. Sacomori C, Silveira C, Sperandio FF, Cardoso FL. Prevalence, repercussion and factors associated with intestinal constipation in women in Florianopolis. $\mathrm{J}$ Coloproctol. 2014;34:254-9. 
33. Sandler RS, Stewart WF, Liberman JN, Ricci JA, Zorich NL. Abdominal pain, bloating, and diarrhea in the United States: Prevalence and impact. Digestive diseases and sciences. 2000;45:1166-71.

34. Santos Junior JCM. Laxantes e purgativos: O paciente e a constipação intestinal Rev Brasil Coloproctol. 2003;23:130-4.

35. Silva AM, Lins, DC, Azevedo SL, Dias BF, Paiva PB. Diagnóstico de enfermagem: Constipação intestinal funcional associado ao estilo de vida. $2010.10^{\circ}$ SINADEn Available from: http://www.abeneventos.com.br/10sinaden/anais/files/0091.pdf

36. Spiegel B, Bolus R, Harris LA, Lucak S, Naliboff B, Esrailian E, et al. Measuring IBS patient reported outcomes with an abdominal pain numeric rating scale: results from the proof cohort. Aliment Pharmacol Ther. 2009;3:1159-70.

37. Sun SX, Dibonaventura M, Purayidathil FW, Wagner JS, Dabbus O, Mody R Impact of chronic constipation on health-related quality of life, work productivity, and healthcare resource use: an analysis of the National Health and Wellness Survey. Dig Dis Sci. 2011;56:2688-95.
38. Tielemans MM, Focks JJ, Rossum LGM, Eikendal T, Jansen JBMJ, Laheij RJF, et al. Gastrointestinal symptoms are still prevalent and negatively impact health-related quality of life: a large cross-sectional population based study in The Netherlands. PlosOne. 2013;8:e69876.

39. Tillisch K, Labus J, Kilpatrick L, Jiang Z, Stains J, Ebrat B, et al. Consumption of fermented milk product with probiotic modulate brain activity. Gastroenterol. 2013;144:1394-401.

40. Van Kerkhoven LA, Eikendal T, Laheij RJ, Van Oijen MG, Jansen JB. Gastrointestinal symptoms are still common in a general Western population. Neth J Med. 2008;66:18-22.

41. Waitzberg DL, Quilici FA, Michzputen S, Passos MCF. The effect of probiotic fermented milk that includes Bifidobacterium lactis CNCM I-2494 on the reduction of gastrointestinal discomfort and symptoms in adults: a narrative review. Nutricion Hospitalaria. 2015;32:501-9. 